\title{
Ecologia de nidificação de abelhas do gênero Partamona (Hymenoptera: Apidae) na caatinga, Milagres, Bahia
}

\author{
Lílian Santos Barreto ${ }^{1,3}$ \& Marina Siqueira de Castro $^{1,2}$ \\ Biota Neotropica v7 (n1) - http://www.biotaneotropica.org.br/v7n1/pt/abstract?article+bn01807012007 \\ Recebido em 15/07/06 \\ Versão reformulada recebida em 20/12/06 \\ Publicado em 31/01/07 \\ ${ }^{1}$ Empresa Baiana de Desenvolvimento Agrícola - EBDA, Laboratório de Abelhas, \\ Av. Ademar de Barros, 967, Ondina, CEP 40170-110, Salvador, BA, Brasil \\ ${ }^{2}$ Universidade Estadual de Feira de Santana - UEFS, Departamento de Ciências Biológicas, \\ BR 116, Km 3, CEP 44031-460, Feira de Santana, BA, Brasil \\ ${ }^{3}$ Autor para correspondência: Lílian Santos Barreto, e-mail: lbarreto@ufba.br
}

\begin{abstract}
Barreto, L.S. \& Castro, M.S. Ecology of nesting of bees of the genus Partamona in caatinga, Milagres, Bahia. Biota Neotrop. Jan/Apr 2007 vol. 7, no. 1 http://www.biotaneotropica.org.br/v7n1/pt/abstract?article+bn01807012007 ISSN 1676-0603.

The species richness, abundance, nesting sites, spatial distribution pattern, density of available substrates and substrates used for nesting by Partamona species were studied in a restricted area of a tropical dry forest/ woodlands ecosystem called "arboreal caatinga" in Milagres, Bahia State, Brazil. Two species of the genus Partamona, occurred in the studied area, Partamona rustica (94.1\%) and Partamona cupira (5.9\%), both nested in arboreal termites nests of the Constrictotermes cyphergaster species. Other three species of arboreal termites' nests occurred in the area (Nasutitermes corniger, Nasutitermes macrocephalus and Microcerotermes sp.). The arboreal termites had nested mainly in "umburana" (Commiphora lepthophloeos). The nesting strategy of Partamona species consist in occupying preexisting cavities opened in arboreal termites nested by a parakeet called "jandaia" (Aratinga cactorum), for reproduction. After the birth of the younglings, the cavity is abandoned and after that a colony of Partamona bees occupies it and starts its nest construction, isolating it with mud and resin. Frequently these cavities are occupied by other inquilines.

Keywords: stingless bees, Partamona, Aratinga cactorum, termites.

Resumo

Barreto, L.S. \& Castro, M.S. Ecologia de nidificação de abelhas do gênero Partamona (Hymenoptera: Apidae) na caatinga, Milagres, Bahia. Biota Neotrop. Jan/Apr 2007 vol. 7, no. 1 http://www.biotaneotropica.org.br/v7n1/pt/abstract?article+bn01807012007 ISSN 1676-0603.

Neste estudo foi analisada a riqueza, a abundância, os sítios de nidificação, o padrão de distribuição espacial, a densidade dos sítios potenciais disponíveis e dos sítios nidificados pelas espécies de abelhas sem ferrão do gênero Partamona e dos termiteiros arbóreos nidificados pelas abelhas, em uma área restrita de caatinga arbórea, em Milagres, Bahia, Brasil. Duas espécies ocorreram em simpatria, Partamona rustica $(94,1 \%)$ e Partamona cupira $(5,9 \%)$, ambas nidificando em termiteiros arbóreos da espécie Constrictotermes cyphergaster. Outras três espécies de termiteiros arbóreos ocorreram na área (Nasutitermes corniger, Nasutitermes macrocephalus e Microcerotermes sp.). Os térmitas arbóreos nidificaram principalmente na umburana (Commiphora leptophloeos). As espécies de abelhas do gênero Partamona têm como estratégia de nidificação na caatinga utilizar cavidades pré-existentes que consistem em ocos abertos em termiteiros arbóreos pelo periquito jandaia (Aratinga cactorum), para reprodução. Após o nascimento dos filhotes, o oco é abandonado e em seguida uma colônia de abelhas do gênero Partamona constrói ali o seu ninho, ocupando-o e isolando-o com geoprópolis, sendo freqüente a ocupação destes ocos por outros inquilinos.
\end{abstract}

Palavras-chave: abelha sem ferrão, Partamona, Aratinga cactorum, termiteiros. 


\section{Introdução}

Partamona Schwarz (1939), é um gênero de abelhas sem ferrão (Hymenoptera, Apidae, Meliponinae) exclusivamente neotropical e de ampla distribuição geográfica, que ocorre desde o sul do Brasil até o México central. Estes insetos podem ser encontrados em ambientes de matas, cerrado, caatinga ou mesmo em regiões montanhosas (cordilheiras andinas e centro-americanas), a mais de 2.000 $\mathrm{m}$ de altitude; algumas espécies toleram bem o ambiente antrópico. São abelhas agressivas que nidificam em uma grande variedade de substratos, sendo que muitas espécies são termitófilas obrigatórias (Pedro \& Camargo 2003). Segundo Camargo \& Pedro (2003) existem 33 espécies reconhecidas para o gênero Partamona, das quais 17 são novas, sendo que algumas espécies só podem ser reconhecidas quanto ao hábito de nidificação e atributos da estrutura de entradas dos ninhos.

Os Meliponinae, em geral, podem construir ninhos aéreos em ocos de árvores, em ninhos de aves, subterrâneos, ou mesmo dentro de ninhos de outros insetos sociais, tais como térmitas e formigas. Um exemplo clássico é o da Trigona cilipes cilipes, a qual pode construir seu ninho tanto dentro de um formigueiro do gênero Azteca, como no interior de termiteiro (Kerr et al. 1967). Os padrões de ocupação destes substratos de nidificação ainda não estão bem definidos, exceto por algumas observações feitas por Wille \& Michener (1973) e Michener (1974). Diversos autores mencionam a construção de ninhos de meliponíneos no interior de termiteiros; e.g. Mariano-Filho (1911), Ducke (1916), Ihering (1930).

A observação mais antiga sobre a ocupação de ninhos de cupins por abelhas indígenas sem ferrão foi feita por Castelo-Branco (1845). Segundo este autor, um pica-pau faz um buraco na casa do cupim, para se alimentar dos moradores ou para ali estabelecer seu ninho, e posteriormente este oco é ocupado pela abelha cupira. $\mathrm{Na}$ vegetação de Cerrado do Mato Grosso, Mathews (1977) encontrou abelhas sem ferrão associadas aos ninhos de Constrictotermes cyphergaster; as abelhas não foram identificadas e havia um termiteiro onde em uma cavidade existia um ninho de periquito. Segundo Wille $\&$ Michener (1973), Partamona cupira faz ninhos em vários lugares e situações bem diferentes, não apenas em termiteiros.

Dentre os representantes do gênero Partamona podemos encontrar espécies que constroem ninhos subterrâneos (Partamona testacea), em ocos de árvores (Partamona sakagamii), em cupinzeiros aéreos (Partamona nigrior), em cupinzeiros no chão (Partamona pearsoni) ou em cupinzeiros semi-aéreos (Partamona cupira) (Camargo 1970). No Nordeste semi-árido, Lorenzon et al. (1999) encontraram ninhos de Partamona dentro de cupinzeiros do gênero Constrictotermes.

Neste estudo pretende-se elucidar as relações ecológicas existentes a cerca da nidificação das abelhas sem ferrão do gênero Partamona, entre os termiteiros utilizados como substratos de nidificação e o periquito Arating a cactorum. Pretende-se também determinar o padrão de distribuição espacial dos ninhos de abelhas do gênero Partamona associadas aos termiteiros arbóreos na caatinga.

\section{Material e Métodos}

\section{1. Área estudo}

Os ninhos de abelhas do gênero Partamona foram observados em seis localidades no período de dezembro de 2000 a dezembro de 2001, em uma área restrita de caatinga arbórea de 4000 hectares. Para cada localidade foi levantado um hectare, perfazendo um total de seis hectares de área amostral localizada em Milagres, Bahia $\left(12^{\circ} 53^{\prime} \mathrm{S}\right.$ e $\left.39^{\circ} 51^{\prime} \mathrm{W}\right)$. O critério adotado para a escolha das localidades foi a presença de sítios nidificados pelas abelhas Partamona em
17 localidades levantadas em outro estudo prévio sobre nidificação de abelhas sem ferrão, em Milagres. Os ninhos de abelhas Partamona e dos termiteiros disponíveis e ocupados foram encontrados através de procura aleatória, com a ajuda de guias locais.

\section{Caracterização dos ninhos das abelhas Partamona (Hymenoptera, Apidae), dos termiteiros (Isoptera, Termitidae), e suas distribuições espaciais}

Em cada termiteiro utilizado pelas abelhas foram tomadas as medidas do comprimento e da largura; bem como da altura em relação ao solo. O material usado na confecção dos termiteiros foi anotado e as espécies arbóreas que continham os ninhos foram identificadas. Quanto aos ninhos das abelhas foram medidos o comprimento e o diâmetro das entradas; anotados o número de entradas e de abelhas-guarda, além do material de construção dos ninhos e das suas ornamentações. As medidas do comprimento e diâmetro dos ocos em que as colônias se alojavam também foram tomadas quando possível. Foi determinado o índice do padrão de distribuição espacial (C) dos ninhos das abelhas e dos termiteiros nidificados pelas abelhas através do método T-square distance sampling (Ludwig \& Reynolds 1988) usando para os cálculos o programa Basic. Tsquare. bas.

Monitoramento dos ninhos de Partamona (Hymenoptera, Apidae) localizados em termiteiros arbóreos e do comportamento reprodutivo de Aratinga cactorum (Aves, Psittacidae). Foram marcados e acompanhados três ninhos de abelhas nidificadas em termiteiros durante o período do estudo, uma vez por mês, durante um ano. A predação, o abandono dos ninhos e a ocupação dos ocos dos termiteiros pelo periquito foram monitorados. O ciclo reprodutivo das aves também foi acompanhado com os registros dos períodos durante o ano de procura por locais de aninhamento, fase pré-postura, cortejamento e cópula, postura dos ovos, incubação e eclosão, desenvolvimento dos ninhegos, morte e desaparecimento dos ninhegos e saída dos mesmos do ninho. Na estação reprodutiva, as fêmeas foram capturadas, colocando-se um puçá na abertura do ninho, sendo posteriormente marcadas com uma anilha colorida em seu tarso. O monitoramento seguiu-se com registros através de observações diretas, fotografias e filmagens com câmera VHS. Para a observação no interior do ninho construído em termiteiros arborícolas, foi feita uma abertura no ápice do cupinzeiro até atingir a câmara incubadora. O pedaço retirado era usado como tampa, sendo cuidadosamente retirado no momento de cada observação e logo recolocado.

\section{Resultados}

Nas seis localidades amostradas foram identificadas duas espécies de abelhas do gênero Partamona, Partamona rustica Pedro \& Camargo (2003) e Partamona cupira Smith, 1863 que nidificaram em termiteiros da espécie Constrictotermes cyphergaster Silvestri (1901) (Tabela 1), com exceção de uma colônia de Partamona rustica que nidificou em termiteiro da espécie Nasutitermes corniger Motschulsky (1855). Foram identificadas cinco espécies de térmitas, dentre estas, aquelas que constroem ninhos em substratos arbóreos ou arbustivos: Constrictotermes cyphergaster (314 ninhos), Nasutitermes macrocephalus (51 ninhos), Nasutitermes corniger (1 ninho), Microcerotermes sp. (1 ninho) e uma espécie que não constrói ninho, Syntermes molestus (1 ninho) que ocupava outro ninho de térmita da espécie Constrictotermes cyphergaster, a uma profundidade de $54 \mathrm{~cm}$ do solo.

O termiteiro arbóreo de Constrictotermes cyphergaster apresentou oito ninhos "ocados" (abertos pelo periquito) e não ocupados por inquilinos; nos ninhos de Nasutitermes macrocephalus foram encontradas duas cavidades pré-existentes não ocupadas. Não se 
Tabela 1. Bases dos estudos de ecologia de nidificação das abelhas Partamona em termiteiros, na caatinga, Milagres, Ba.

Table 1. Bases of the studies of ecology of nest building of the Partamona bees in termites, in caatinga, Milagres, Ba.

\begin{tabular}{|c|c|c|c|c|c|c|}
\hline \multirow{2}{*}{$\begin{array}{c}\text { Base } \\
\text { amostral }\end{array}$} & \multirow[t]{2}{*}{ Fisionomia geral } & \multirow{2}{*}{$\begin{array}{l}\text { Coordenadas } \\
\text { geográficas }\end{array}$} & \multirow{2}{*}{$\begin{array}{c}\text { Ninhos } \\
\text { abelhas }\left(\mathbf{n}^{\circ}\right) \\
\text { Partamona }\end{array}$} & \multicolumn{2}{|c|}{ Ninhos térmitas $\left(n^{0}\right)$} & \multirow[t]{2}{*}{ Área } \\
\hline & & & & C. cyphergaster & N. macrocephalus & \\
\hline B 01 & $\begin{array}{l}\text { Lagoa cujas margens ficam cobertas de plantas } \\
\text { aquáticas da família Pontederiaceae. Nos arre- } \\
\text { dores da lagoa, ocorrem árvores de porte médio } \\
\text { a alto e cactáceas. }\end{array}$ & $\begin{array}{l}12^{\circ} 47^{\prime} 13^{\prime \prime} \mathrm{S} \mathrm{e} \\
39^{\circ} 50^{\prime} 022^{\prime \prime} \mathrm{W}\end{array}$ & 3 & 38 & 8 & 1 ha \\
\hline В 02 & $\begin{array}{l}\text { Lagoa situada em um lajedo, com muitos agru- } \\
\text { pamentos de bromélias e cactos. O seu entorno é } \\
\text { formado por uma caatinga arbórea arbustiva. }\end{array}$ & $\begin{array}{l}12^{\circ} 46^{\prime} 43^{\prime \prime} \mathrm{S} \mathrm{e} \\
39^{\circ} 51^{\prime} 57^{\prime \prime} \mathrm{W}\end{array}$ & 3 & 52 & 15 & 1 ha \\
\hline В 03 & $\begin{array}{l}\text { Caatinga arbórea-arbustiva com maior con- } \\
\text { centração de árvores nas margens do rio (mata } \\
\text { ciliar). }\end{array}$ & $\begin{array}{l}12^{\circ} 47^{\prime} 46^{\prime \prime} \mathrm{S} \mathrm{e} \\
39^{\circ} 50^{\prime} 36^{\prime \prime} \mathrm{W}\end{array}$ & 1 & 37 & 4 & 1 ha \\
\hline В 04 & $\begin{array}{l}\text { Caatinga arbórea-arbustiva alta, com palmeiras. } \\
\text { Com árvores acima de } 8 \mathrm{~m} \text { formando um dossel, } \\
\text { ocorrendo ao longo do rio. }\end{array}$ & $\begin{array}{l}12^{\circ} 47^{\prime} 53 ” \mathrm{~S} \mathrm{e} \\
39^{\circ} 51^{\prime} 55^{\prime \prime} \mathrm{W}\end{array}$ & 5 & 81 & 15 & 1 ha \\
\hline В 05 & $\begin{array}{l}\text { Caatinga arbórea-arbustiva baixa e fechada; } \\
\text { com presença de Cactaceae. }\end{array}$ & $\begin{array}{l}12^{\circ} 47^{\prime} 51^{\prime \prime} \mathrm{S} \mathrm{e} \\
39^{\circ} 51^{\prime} 16^{\prime \prime} \mathrm{W}\end{array}$ & 3 & - & - & 1 ha \\
\hline В 06 & $\begin{array}{l}\text { Caatinga arbórea-arbustiva, bastante descarac- } \\
\text { terizada pela prática do roçado e queimadas. }\end{array}$ & $\begin{array}{l}12^{\circ} 46^{\prime} \mathrm{S} \text { e } \\
40^{\circ} 13^{\prime} \mathrm{W}\end{array}$ & 2 & 106 & 9 & 1 ha \\
\hline Total & & & 17 & 314 & 51 & 6 ha \\
\hline
\end{tabular}

constatou ninhos de Microcerotermes sp. e Nasutitermes corniger com cavidades pré-existentes.

Os termiteiros de Constrictotermes cyphergaster nidificados pelas abelhas Partamona foram construídos com areia ou argila, e a largura e comprimento $(X=63,45 \mathrm{~cm} \pm 24,04$; $\mathrm{X}=39,22 \mathrm{~cm} \pm 7,20, \mathrm{n}=25$ ) foram maiores que os termiteiros da espécie Nasutitermes macrocephalus $(X=71,83 \mathrm{~cm} \pm 27,36$; $\mathrm{X}=55,83 \mathrm{~cm} \pm 11,79, \mathrm{n}=3$ ) que apresentavam ocos feitos pelo periquito, mas não ocupados pelas abelhas e cujo material empregado na construção do ninho era matéria orgânica vegetal seca, na qual se misturam partículas de madeira ou de terra de natureza proctodeica, o que lhes dá o aspecto cartonado característico. Termiteiros arbóreos de $\mathrm{N}$. macrocephalus se encontravam a alturas maiores $(\mathrm{X}=2,17 \mathrm{~m} \pm 36,01, \mathrm{n}=3$ ) quando comparados com os de C. cyphergaster $(\mathrm{X}=1,37 \mathrm{~m} \pm 77,21, \mathrm{n}=25)$.

Foi observado que quando uma parte do ninho de Nasutitermes macrocephalus se desfaz, esta é rapidamente refeita, enquanto que Constrictotermes cyphergaster levava mais tempo para reconstituir a parte do cupinzeiro danificada. Quanto à agressividade dos ninhos de Nasutitermes corniger e Constrictotermes cyphergaster, constatou-se que ao introduzir a mão dentro dos ocos para as mensurações, os térmitas da espécie Nasutitermes corniger "mordiam" o intruso, enquanto que os da espécie Constrictotermes cyphergaster não exibiam este comportamento defensivo.

O oco dentro do termiteiro da espécie Constrictotermes cyphergaster ocupado pelas abelhas Partamona possuiu comprimento $(X=21,58 \mathrm{~cm} \pm 7,99 ; \mathrm{n}=5)$ maior que a largura $(X=17,82 \mathrm{~cm} \pm 7,6 ; n=5)$. As abelhas empregavam resina no revestimento e na construção da entrada, esta com diâmetro de $0,64 \mathrm{~cm}$.

As espécies arbóreas mais utilizadas como substratos para a sustentação dos termiteiros da espécie Constrictotermes cyphergaster ( $\mathrm{n}=314)$ foram: Commiphora leptophloeos Mart. (11,15\%), Psidium sp. (5,1\%), Caesalpinia pyramidalis Tul. $(3,18 \%)$ e Spondias tuberosa Arr. Cam. (2,55\%); apesar de 54,5\% dos ninhos terem sido levantados em substratos herbáceos próximos ao solo.
O padrão de distribuição espacial dos ninhos das abelhas sem ferrão do gênero Partamona e dos termiteiros da espécie Constrictotermes cyphergaster foi agregado (Tabela 2). Na área total, a densidade dos ninhos de Partamona, de Constrictotermes cyphergaster e Nasutitermes macrocephalus, são respectivamente 2,8 ninhos/ha, 62,8 ninhos/ha e 10,2 ninhos/ha.

Os substratos nidificados pelas abelhas Partamona são as cavidades pré-existentes (ocos) feitas pelo periquito Aratinga cactorum em termiteiros arbóreos da espécie Constrictotermes cyphergaster. A ocupação pelas abelhas de ocos pré-existentes nos termiteiros ocorreu em cavidades que tinham sido construídas, ocupadas e abandonadas pelo periquito jandaia (Aratinga cactorum), após o nascimento dos filhotes. Em um novo ciclo reprodutivo dos periquitos, foram constatados dois ninhos de Partamona predados pelos mesmos para reocupação do oco.

De acordo com o "ciclo de furação" dos termiteiros, ou seja, abertura de ocos em termiteiros pelos periquitos jandaia (Aratinga cactorum) como resultado do seu comportamento reprodutivo por locais de aninhamento, foi verificado um padrão de ocupação temporal e espacial dos locais de nidificação das aves e das abelhas sem ferrão. Ou seja, a ocupação espacial (ninhos de térmitas arbóreos) e a ocupação temporal (época do ano) são características para cada espécie inquilina do termiteiro (Figura 1).

Entre os meses de maio e julho foi observada ocupação dos ocos abandonados por outros inquilinos (abelhas africanizadas (Apis mellifera L.), aves, formigas, roedores, vespas e rãs), todos em diferentes ocos da espécie Constrictotermes cyphergaster. Em termiteiros de Nasutitermes macrocephalus foi observado um ninho de Apis mellifera abandonado.

A saída dos filhotes das aves dos ninhos antecedeu o período de maio a julho de 2001, período este que os ocos dos termiteiros não mais ocupados pelos filhotes das aves encontravam-se sem inquilinos e que coincidia com a fase de enxameagem das abelhas Partamona, isto é, da divisão natural dos seus ninhos, que passaram a ocupar estes ocos. 


\begin{tabular}{|c|c|c|c|c|c|c|c|c|c|c|c|}
\hline Jan & $\mathrm{Fev}$ & Mar & Abr & Mai & Jun & Jul & Ago & Set & Out & Nov & Dez \\
\hline \multicolumn{12}{|c|}{ AT } \\
\hline \multicolumn{2}{|c|}{ MDN } & \multicolumn{2}{|c|}{ SN } & \multicolumn{3}{|c|}{ Ol } & & LA & \multicolumn{2}{|r|}{ FPP } & \\
\hline \multicolumn{2}{|c|}{$\mathrm{DN}$} & & & \multicolumn{3}{|c|}{ EN } & & & & \multicolumn{2}{|c|}{$\mathrm{CC}$} \\
\hline IE & & & & & & & & & & & $\mathrm{IE}$ \\
\hline
\end{tabular}

AT = atividade de construção do ninho pelos térmitas; MDN = morte e desaparecimento dos ninhegos; SN = saída dos ninhegos do ninho; OI = ocupação dos ocos por inquilinos; LA = procura do periquto por locais de aninhamento; FPP = fase pré-postura (fim da construção do ninho e inicio da postura dos ovos das aves); $\mathrm{DN}=$ desenvolvimento dos ninhegos, $\mathrm{EN}=$ Enxameagem das abelhas Partanoma; CC = cortejamento e cópula; $\mathrm{IE}=$ incubação e eclosão; $\mathrm{P}=$ postura dos ovos das aves.

Figura 1. Ciclo reprodutivo do periquito Aratinga cactorum por locais de aninhamento e ocupação dos ocos abandonados em termiteiros arbóreos, na caatinga, Milagres, Ba.

Figure 1. Reproductive cycle of the parakeet Aratinga cactorum for nesting places and occupation of the hollow ones abandoning in arboreal termites, in caatinga, Milagres, Ba.

Tabela 2. Padrão de distribuição espacial dos ninhos de Partamona e dos termiteiros Constrictotermes cyphergaster determinado através do método T-square distance sampling (Ludwig \& Reynolds 1988), em Milagres, Ba.

Table 2. Standard of space distribution of the nests of Partamona and the termites Constrictotermes cyphergaster to definitive through the method T-square distance sampling (Ludwig \& Reynolds 1988) in Milagres, Ba.

\begin{tabular}{|c|c|c|}
\hline & $\begin{array}{c}\text { Partamona } \\
(\mathrm{n}=17)\end{array}$ & $\begin{array}{l}\text { Constrictotermes cyphergaster } \\
\qquad(\mathrm{n}=32)\end{array}$ \\
\hline Primeiro vizinho $(\mathrm{x})$ & Média $=53,20$ & Média $=11,60$ \\
\hline Vizinho mais próximo $(y)$ & Média $=62,20$ & Média = 5,20 \\
\hline \multirow[t]{3}{*}{ Índice de agregação } & $\mathrm{C}=0,65$ & $\mathrm{C}=0,81$ \\
\hline & $Z=1,13$ & $Z=2,42$ \\
\hline & $\mathrm{P}<0,01$ & $\mathrm{P}<0,01$ \\
\hline
\end{tabular}

\section{Discussão}

O gênero Partamona está quase que estritamente ligado em seu hábito de nidificação aos térmitas. A maior parte das espécies que nidifica acima do solo constrói seu ninho em termiteiros vivos ou abandonados (Camargo 1980). Geralmente as espécies de térmitas que fazem ninhos arbóreos constroem o termiteiro sobre o solo ou mesmo semi-enterrado (Costa-Lima 1939), como observado neste estudo com os termiteiros da espécie Constrictotermes cyphergaster, que apresentou maior variação de substratos nidificados que a espécie Nasutitermes macrocephalus.

Segundo Roubik (1989), as abelhas sem ferrão usam cavidades pré-existentes; elas não as constroem, dependendo assim da sua ocorrência natural. De acordo com Smith (1952), espécies do gênero Melipona entram em ninhos subterrâneos de térmitas. Apesar da existência de uma "corbícula" mais alargada e estruturada para manusear o barro, não foram observados ocos que tenham sido feitos por estas abelhas, capazes de abrigar suas colônias. No presente estudo, os ninhos de Partamona foram construídos em cavidades pré-existentes em termiteiros arbóreos da espécie Constrictotermes cyphergaster, nos quais as cavidades eram feitas pelo periquito Aratinga cactorum, com a finalidade de abrigar a sua prole.

O padrão agregado de distribuição espacial dos ninhos das abelhas Partamona está relacionado tanto ao padrão também agregado dos seus substratos de nidificação, os termiteiros da espécie
Constrictotermes cyphergaster, como também ao comportamento do periquito de ocar os termiteiros próximos. Em estudo realizado no Cerrado, por Lima-Barreto et al. (2006), C. cyphergaster não seleciona as espécies vegetais nas quais construirão seus ninhos aleatoriamente ou de acordo com a abundância, mas possui preferência por algumas espécies particulares.

A dinâmica de distribuição e a posição espacial de cada indivíduo de uma população, em um dado momento, dependem da configuração dos recursos necessários para a sobrevivência da espécie e da distribuição dos demais organismos simpátricos e de suas interferências (Laroca 1995). Conseqüentemente, a nidificação das abelhas Partamona apenas em ninhos da espécie C. cyphergaster, pode estar relacionada a alta densidade desses ninhos na área quando comparamos com a outra espécie em simpatria $N$. macrocephalus que apresentou menor número de ninhos ocados pelos periquitos.

Sabendo-se que as relações simbióticas podem ser parasíticas ou mutualísticas, de um modo geral, as relações entre abelhas e térmitas e entre periquitos e térmitas apontam para uma relação do tipo mutualismo defensivo na qual envolve uma espécie que recebe abrigo (abelhas ou periquitos) de seu parceiro (térmitas) em troca de defesa contra predadores, uma relação entre duas espécies com benefícios para ambas. As relações mais específicas entre térmitas e abelhas não foram observadas neste trabalho para melhor investigar se realmente existe vantagem ou desvantagem para os termiteiros em serem substratos de nidificação. Segundo Odum (1985) o tipo de interação pode 
mudar sob diferentes condições ou durante estádios sucessivos nas suas bionomias. No entanto parece que a própolis, resina das plantas coletada pelas abelhas, e usada na defesa e calefação de seus ninhos, pode ser responsável por boa parte da proteção dos termiteiros, já que as abelhas isolam suas colônias construídas no interior do termiteiro dos mesmos, calafetando todo o oco ocupado com a própolis.

Em relação aos térmitas, tanto as abelhas como o casal de periquitos poderiam ter oferecido defesa ao termiteiro de outros predadores inoportunos. Estudos realizados por Nates \& Cepeda (1983) consideram que as cupiras (abelhas do gênero Partamona) possivelmente façam uso de produtos da sua glândula mandibular, como alomônios que limitam as defesas físicas e comportamentais dos térmitas. O termiteiro seria, portanto, um hospedeiro, por oferecer abrigo para outros organismos, enquanto que seus hóspedes seriam apenas "tolerados" em troca da defesa do ninho.

Primeiramente as abelhas ocupam oportunisticamente os ocos construídos pelos periquitos, pois estas não possuem estruturas morfológicas capazes de fazê-los. A corbícula mais profunda e alargada da Partamona a capacita a revolver terra, mas não a fazer um oco capaz de abrigar todo o seu ninho. Em um segundo momento, as abelhas passam a ser inquilinas permanentes do cupinzeiro, uma vez que suas colônias são perenes, e para que haja reocupação do oco pelo periquito a colônia de abelhas é predada.

Segundo Sick (1997) o interior dos cupinzeiros arbóreos oferece um ambiente favorável (microclima) considerando temperatura e umidade constantes para os psitacídeos. Em relação ao casal de periquitos, no primeiro momento eles são inquilinos temporários dos termiteiros, período correspondente à fase de postura dos ovos. Em um segundo momento do ciclo reprodutivo de reocupação do oco, caso não encontre uma colônia de abelhas instalada, continuará como um inquilino temporário do termiteiro. Caso encontre uma colônia de abelhas nidificada no oco que havia sido ocupado nas ninhadas anteriores pelo casal, este passa a ser predador da colônia de abelhas. Em um terceiro momento, o casal passa de predador a um oportunista do oco revestido, pois parece se aproveitar do revestimento de própolis dos ocos ocupados pelas abelhas, pois se sabe que a própolis possui atividades biológicas e propriedades antibacterianas, o que estaria assegurando a proteção das crias e a sanidade dos filhotes das aves.

De acordo com Costa Lima (1939), quando se explora um termiteiro, encontra-se sempre, além do térmita, legítimo proprietário, vários inquilinos, uns que penetram acidentalmente, outros, que se estabelecem definitivamente na sociedade. São estes chamados de termitófilos, de aspecto quase sempre interessante, devido a uma adaptação mais ou menos perfeita às condições particulares do meio em que vivem que os tornam, não raro, incapazes de viver independentemente.

A coexistência de abelhas com outros insetos sociais tem sido descrita por vários autores. Segundo Nogueira-Neto (1953), algumas das espécies das formigas que fazem seus ninhos nas frestas que possam existir nas colméias, pouco prejudicam as colônias, uma vez que as formigas podem até afugentar um predador, defendendo a colônia de abelhas de um ataque inimigo. Birket- Smith (1957), descrevendo ninhos de Apis mellifera, encontrou formigas de várias espécies, porém não parecendo acarretar inconveniências às abelhas. Smith (1954), em estudos na África observou Trigona denoiti nidificando em cupinzeiros e os térmitas pareceram indiferentes a presença das abelhas; porém, se uma delas cai entre os cupins é imediatamente atacada. Os térmitas, por sua vez, não atacam a parte exposta do ninho e podem, às vezes, ficar presos nas resinas que envolvem a entrada. Kempf-Mercado (1962) relata o caso de Trigona compressa e T. crematogaster vivendo juntas, colocando esta relação na categoria de mutualismo. Camargo (1984) descreve a estratégia de ocupação progressiva de cupinzeiros pela abelha sem ferrão Scaura latitarsis, que para aumentar o seu ninho constrói pequenas câmaras de cera e resina fixadas à parede da cavidade interna do cupinzeiro, trabalhando dentro dessas câmaras, raspando e modificando as galerias do cupinzeiro, ficando seguras contra a invasão dos térmitas; o autor concluiu ser esta uma estratégia de valor adaptativo seguro e engenhosa, além das abelhas se beneficiarem da proteção e da estabilidade térmica do termiteiro. Silvestri (1903) observou uma relação simbiótica entre Nasutitermes rippertii e abelhas sem ferrão do gênero Trigona, que fazem o ninho na parte central ou inferior dos cupinzeiros arborícolas, isolando-o do resto do termiteiro por uma camada espessa e dura de própolis. Pickel (1928) descreve como Centris sponsa vive em cupinzeiros de Microcerotermes bouvieri, classificando como uma relação de simbiose que se limita à ocupação por meios violentos de uma parte do cupinzeiro pela abelha, sem que entre nos canais e sem viver à custa do primeiro, apoderando-se de um lugar para a cria e depois o abandona.

Observações realizadas por Wille \& Orozco (1975) sobre a formação de uma nova colônia de Partamona cupira na Costa Rica em um ninho abandonado de termitas da espécie Nasutitermes sp., antes ocupado por um ninho de Scaura latitarsis, possibilitou concluir que não existe uma forte dependência com ninho mãe, como suspeitado, e a conexão com o ninho mãe durante a enxameagem é a maior que se conhece entre os meliponíneos, com duração de seis meses.

Em um estudo realizado na região do semiárido no estado da Paraíba por Lorenzon et al. (1999), sobre as relações entre Partamona aff. nigrior e termiteiros da espécie Constrictotermes sp. n., os autores chegaram a conclusão que a relação entre as duas espécies é, sem dúvida, não mutualística e que as abelhas (hóspedes) parecem apenas se beneficiar do termiteiro como local de nidificação, uma vez que os térmitas são com o tempo deslocados para a periferia dos ninhos e por fim completamente eliminados. Os autores concluíram, também, que os ninhos de Constrictotermes sp. n., ativos ou não, devem fornecer condições essenciais para a sobrevivência de Partamona aff. nigrior, condições estas possivelmente relacionadas com temperatura, umidade e proteção física.

A partir de dados da literatura e dos padrões observados neste trabalho, pode-se inferir que algumas espécies de abelhas do gênero Partamona encontram nos ocos de termiteiros da espécie Constrictotermes cyphergaster um local propício para nidificação na área de caatinga.

\section{Agradecimentos}

A Empresa Baiana de Desenvolvimento Agrícola (EBDA) pelo apoio logístico e financeiro. À Dra. Silvia R. M. Pedro (FFCLRP) pela identificação das espécies de Partamona. Ao Dr. Reginaldo Constantino (UnB) pela identificação dos térmitas. Ao Dr. Caio Graco (UEFS) pela identificação do periquito. Ao técnico José Xavier de Jesus (EBDA) pelo apoio em campo. Aos guias locais Liu (Marli L. Santos), Tonho (Antônio L. Santos) e Béu (Abéu L. Santos) e a D. Olga Ávila Ribeiro e à sua filha Maria Luiza Ávila Ribeiro, proprietárias da Fazenda Bastião, onde foi realizado todo o trabalho de campo.

\section{Referências Bibliográficas}

BIRKET- SMITH, J. 1957. Honey-bees in Southern Nigeria. Nature, 180:511-512.

CAMARGO, J.M.F. 1970. Ninhos e biologia de algumas espécies de meliponíneos (Hymenoptera: Apidae) da região de Porto Velho, Território de Rôndonia, Brasil. Rev. Biol. Trop. San Jose, Costa Rica, 16(2):207-239.

CAMARGO, J.M.F. 1980. O grupo Partamona (Partamona) testacea (Klung): suas espécies, distribuição e diferenciação geográfica (Meliponinae, Apidae, Hymenoptera). Acta Amazônica, Manaus, 10(4):1-175. Sup 1. 
CAMARGO, J.M.F. 1984. Notas sobre habitos de nidificação de Scaura (Scaura) latitarsis (Friese). Bol. Mus. Paraense Emilio Goeldi, Zool, 1(1):89-95.

CAMARGO, JOÃO M. F. \& PEDRO, SILVIA R. M. 2003. Meliponini neotropicais: o gênero Partamona Schwarz, 1939 (Hymenoptera, Apidae, Apinae) - bionomia e biogeografia. Rev. Bras. entomol. 47(3):311-372.

CASTELO-BRANCO, L.S.D. 1845. Memória acerca das abelhas da Província do Piauhy no Império do Brasil. O Auxiliador da Indústria Nacional. 2/3:49-72.

COSTA-LIMA, A. 1939. Insetos do Brasil, $1^{\circ}$ tomo. Esc. Nac. Agron., série didática. n.2, 470p.

DUCKE, A. Himenópteros. 1916. Publicação 35 da Comissão de Linhas Telegr. Estratégicas de Mato Grosso ao Amazonas. Conselho Nacional de Proteção aos Índios, Ministério da Agricultura, RJ, 133p.

IHERING, H. 1930. Biologia das abelhas melíferas do Brasil. Bol. Agr. da Secr. Agr. do Est. São Paulo, 31(5/8):435-506, 649-714.

KEMPF-MERCADO, N. 1962. Mutualism between Trigona compressa Latr. and Crematogaster stolli Forel. (Hymenoptera, Apidae). J. New York Ent. Soc. 50(4):215-217.

KERR, W.E., SAKAGAMI, S.F., ZUCCHI, R., ARAUJO, V. de P. \& CAMARGO, J.M.F. 1967. Observações sobre a arquitetura dos ninhos e comportamento de algumas espécies de abelhas sem ferrão das vizinhanças de Manaus, Amazonas (Hymenoptera: Apoidea). Atas. Simp. Biota Amazônica, Manaus, AM, 5:255-309.

LAROCA, S. 1995. Ecologia. Princípios e Métodos. Petrópolis, RJ, Ed. Vozes. 197p.

LIMA-RIBEIRO, MATHEUS de S., PINTO, MÍRIAM P., COSTA, \& SHIRLEY, S.L. 2006. Associação de Constrictotermes cyphergaster Silvestri (Isoptera: Termitidae) com espécies arbóreas do Cerrado brasileiro. Neotrop. Entomol. 35(1):49-55.

LORENZON, M. C., BANDEIRA, A., AQUINO, H. \& MARACAJÁ-FILHO, N. 1999. Relationship between Partamona (HYM., APIDAE) and Constrictotermes (ISOP., TERMITIDAE) in the semiarid region of the Paraíba state, Brazil. Revta. Nordest. Biol. 13(1/2):61-68.

LUDWIG, J.A. \& REYNOLDS J.F. 1988. Statistical Ecology: A Primer on Methods and Computing. New York: John Wiley \& Sons, 337p.

MARIANNO-FILHO, J. 1911. Ensaio sobre as Meliponidas do Brasil. Rio de Janeiro, RJ: Edição do autor, 140p.

MATHEWS, A.G.A. 1977. Studies on termites from the Mato Grosso state, Brazil, Rio de Janeiro, RJ: Academia Brasileira de Ciências, 267p.

MICHENER, C.D. 1974. The social behavior of the bees. Belknap Press of Harvard Universidade and University Press, Cambridge, Mass, 404p.

NATES, G., CEPEDA, O. 1983. Comportamiento defensivo en algunas especies de meliponíneos colombianos. Bol. Dept. Biol.Univ. Nac. Colombia, 1:65-81.
NOGUEIRA- NETO, P. 1953. A criação de abelhas sem ferrão. São Paulo, SP; Ed. Chácaras e Quintais, 280p.

ODUM, E.P. 1985. Ecologia. Tradução por Christopher J. Tribe. Rio de Janeiro: Editora Guanabara Koogan, 434p.

PEDRO, S.R.M. \& JOÃO CAMARGO, M.F. 2003. Meliponini neotropicais: o gênero Partamona Schwarz, 1939 (Hymenoptera, Apidae). Rev. Bras. entomol. 47(11):1-117.

PICKEL, B. 1928. Contribuição para a biologia de Centris sponsa e Acanthopus excellens (Hymenoptera). Boletim Biológico, 14:135-143.

ROUBIK, D.W. 1989. Ecology and Natural History of Tropical Bees. Cambridge Univ. Press, 514p.

SICK, H. 1997. Ornitologia Brasileira. Brasília, Ed. Nova Fronteira, $3^{\text {a }}$ ed., $758 \mathrm{p}$.

SILVESTRI, F. 1903. Contribuzione alla conoscenza dei Termitidi e Termitofili dell' America Meridionale. Redia, 1:1-235.

SMITH, F.G. 1952. Bee-keeping observations in Tanganyika. East. African Agric. Journ. 18(2):1-3.

SMITH, F.G. 1954. Notes on the biology and waxes of four species of African Trigona bees (Hymenoptera, Apidae) Proc. Roy. Ent. Soc. 29(4/6):62-70.

WILLE, A., MICHENER, C.D. 1973. The nest architecture of stingless bees with special reference to those of Costa Rica (Hymenoptera, Apidae). Revta Biol. Trop., Universidade de Costa Rica, v.21, Supl.1.

WILLE A; OROZCO E. 1975. Observations on the founding of a new colony by Trigona cupira (Hymenoptera: Apidae) in Costa Rica. Rev. Biol. Trop. 22(2):253-287.

Título: Ecologia de nidificação de abelhas do gênero Partamona (Hymenoptera: Apidae) na caatinga, Milagres, Bahia.

Author: Barreto, LS e Castro, MS

Biota Neotropica, Vol.7 (número 1): 2007 http://www.biotaneotropica.org.br/v7n1/pt/abstract?article+ bn01807012007

Recebido em 15/07/06 - Versão reformulada recebida em - 20/12/06 - Publicado em 31/01/07

ISSN 1676-0603 